\title{
A Planning Tool for the Automated Quantification and Visualization of Blue Space
}

\author{
Julia Hellmanns ${ }^{1,2} \cdot J^{\prime}$ ochen Schiewe ${ }^{2} \cdot$ Thomas Kistemann $^{3} \cdot$ Christoph Höser $^{3}$
}

(c) Deutsche Gesellschaft für Kartographie e.V. 2019

\begin{abstract}
The availability of water surfaces in urban areas (urban blue space) has a positive effect on people's health and well-being. To take this knowledge into account in planning processes, the urban blue space should be quantified. Urban blue space is defined as all visible and accessible water surfaces, with the intrinsic characteristic of being located in populated areas. To assess the visibility of urban blue spaces, individual buildings as well as parts of one building can be evaluated according to the relative visibility of the waters from these locations and vice versa. This report presents the evolution of a workflow to quantify the urban blue space. First, the workflow generates viewpoints on building surfaces by floor, based on a 3D city model. In the next step, a visibility analysis is performed and, finally, the visible urban blue space is quantified for each viewpoint. The quantification and its visualization are performed for both ends of the line of sight: the measure of visible urban blue spaces for each viewpoint is represented on the building facade and the visibility frequency from all viewpoints is evaluated for each part of urban blue space.
\end{abstract}

Keywords Visibility analysis $\cdot$ Blue space $\cdot$ Planning tool $\cdot$ 3D city model $\cdot$ Urban blue space

\section{Zusammenfassung}

Ein Planungstool zur automatisierten Quantifizierung und zur Visualisierung des Themas Stadtblau

Das Vorhandensein von Wasserflächen im urbanen Raum wirkt sich positiv auf die Gesundheit und das Wohlbefinden der Menschen aus. Um diese Erkenntnis in Planungsprozessen zu berücksichtigen, ist eine Quantifizierung von Stadtblau notwendig. Als Stadtblau werden alle sichtbaren und erlebbaren urbanen Oberflächengewässer bezeichnet. Charakteristisch ist dabei die Lage der Gewässer im bebauten und besiedelten Raum. Durch die Ermittlung von Sichtbarkeiten werden Gebäude im Hinblick auf sichtbare Gewässer bewertet. Dieser Bericht stellt die Entwicklung eines Workflows dar, der auf der Grundlage eines 3D-Stadtmodells Sichtpunkte stockwerkspezifisch an Gebäuden generiert, anschließend eine Sichtbarkeitsanalyse durchführt und schließlich für jeden Sichtpunkt das sichtbare Stadtblau quantifiziert. Zur Visualisierung werden die Ergebnisse des sichtbaren Stadtblau von den Sichtpunkten auf die Gebäudefassade übertragen sowie das Stadtblau im Hinblick auf die Häufigkeit einer bestehenden Sichtbarkeit bewertet.

Julia Hellmanns

jhellmanns@gmx.de

Jochen Schiewe

jochen.schiewe@hcu-hamburg.de

Thomas Kistemann

thomas.kistemann@ukbonn.de

Christoph Höser

christoph.hoeser@ukbonn.de

Bonn, Germany

2 HafenCity University Hamburg, Hamburg, Germany

3 University Clinics Bonn, Institute for Hygiene and Public

Health (IHPH), GeoHealth Center, Bonn, Germany 
Schlüsselwörter Sichtbarkeitsanalyse · Stadtblau · Planungstool · 3D-Stadtmodell · Urbane Blauräume

\section{Introduction}

The presence of visible water surfaces in urban areas, also known as blue space, has a positive effect on the health and well-being of people. "Urban blue spaces offer the urban population a variety of opportunities for recreation and leisure, thereby contributing to health promotion near their homes" (translated from Kistemann and Völker 2014, p. 9). However, to take this finding into account in planning processes for health-promoting urban development, a quantitative evaluation method of blue space is necessary. In addition to the presence of bodies of water in the immediate vicinity of a residential area, the actual view of the water is important. Blue space refers to not only tangible but above all visible urban surface waters. Thus, an indispensable characteristic is the location of these bodies of water in a built-up and populated area. The functions and uses of water in urban areas have changed dramatically over the course of time as a function of economic development.

"The City at the Water", "The New Trend: Apartments at the Water" and "Paradise at the Water" are all headlines that make the current trend of residing, working and living nearby water clear. Whether Hamburg, Cologne or Bonn, these cities all benefit from their location close to water. The transformation of former port facilities into residential and working quarters affords a proximity to the water that nowadays means a new quality of life. More and more cities, municipalities and their citizens are rediscovering blue space either as an oasis of nature in the urban environment, a place of recreation and esthetics, a creative element in urban development, or as a meeting place for cultural and sporting activities (Kistemann and Völker 2014). Today, these blue spaces contribute significantly to the design of settlement areas, promoting health and social harmony.

To strengthen the importance of blue space for health, it is necessary to further develop methodical and data-based approaches and to include them in planning processes (Schmidt et al. 2017). This report presents the development and prototypical implementation of a planning tool for evaluating buildings with regard to quantifiably visible blue space. Visibility analyses examine the urban environment with respect to visible surface waters, starting from viewpoints on buildings.

\section{Visibility Analysis}

Visibility analyses are currently widely used for construction projects and in planning processes. In urban and landscape planning, these analyses can clarify how buildings or groundmass movements fit into the landscape or into an existing infrastructure (Graf 2006). Thus, planning scenarios and visibility obstructions can be estimated and presented realistically. Line of sight and viewshed analyses are the two basic methods for analyzing visibility in the GIS environment. A line of sight analysis is used to determine whether a target point is visible from a given point of view. If the line of sight is not obstructed from a terrain point or other object on the earth's surface, the target is visible. In addition to the terrain, obstructions may also be vegetation, buildings and bridges as well as all other urban constructs. In a viewshed analysis, visible and non-visible areas of the terrain surface are determined around a viewpoint.

A quantification of visible blue space will be done through the assessment of buildings in regard to visible bodies of water. After comparison of the two methods for analyzing visibility, line of sight offers some advantages for quantifying blue space. In addition to an assessment of the water bodies in terms of the frequency of their visibility, the focus can be placed on desired target features. Since a visual assessment of the quantification of blue space needs only to be carried out on the surrounding water bodies, a $360^{\circ}$ analysis of the entire environment is not necessary. Nonetheless, line of sight allows the specification of any number of target features. To visualize the results and generate viewpoints, a $3 \mathrm{D}$ city model is used in the planning tool. This model also serves to describe the obstructions in the line of sight. The viewshed analysis, on the other hand, is based exclusively on a surface grid. With a variety of optional parameters such as atmospheric refraction or vertical error, this method is suitable for large-scale analysis. However, for small-scale analyses in urban areas and to obtain further parameters such as the distance between source and target points, the line of sight method is used in the planning tool. Therefore, the viewshed analysis method was not further addressed here.

In this study, the quantification of blue space was carried out with tools from ArcGIS Pro. With the 3D Analyst extension and the Visibility toolbox, ArcGIS Pro provides visibility analysis tools. Based on line of sight, the Intervisibility tool checks for visibility.

\section{Workflow and Implementation}

For the planning tool, a workflow was developed using the Python programming language and the modules of the ArcPy site package to perform a visibility analysis based on observer points on building facades. The building façades are divided into several elements for this purpose and for subsequent visualization according to floor height and a variable 
horizontal width. An observer point is then created for each of these elements (cf. Sect. 3.2). If one assumes that these points represent window openings, then one can speak here not only a floor-specific, but even a window-specific evaluation of the visible blue space area. Target objects of the visibility analysis are bodies of water. Since not only complete bodies of water but also partial areas are to be checked for visibility, the water bodies are used as a grid (cf. Sect. 3.3).

The entire workflow consists of two parts (see Figs. 1, 2). The first describes the division of the facades into smaller elements and the subsequent creation of the observation points on these surfaces. In the second part, these observer points are introduced as input parameters into the visibility analysis and the subsequent evaluation quantifies the visible blue space per point. The result is finally transferred to the façade surfaces for visualization. Figure 3 shows the user interface of the developed planning tool.

\subsection{Data Basis}

Different sets of data are needed for the analysis. To describe the visual obstacles and to generate visual points, a 3D city model is used in the CityGML standard with the LoD2 degree of detail. As a height model, a combination of a digital terrain model (DTM) and a digital surface model (DSM) is introduced in the analysis. Since the DSM depicts the earth's surface with all the objects on it, it also describes the roof heights in the area of buildings. These conflict with the elevation values of the observer points. With a small horizontal offset and distributed over the floors, the points are located directly on the building facades. At these points, elevation data from the DTM, i.e. the mapping of the earth's surface without objects, are necessary. Also important are the heights of the water bodies that are relevant for the quantification of visible blue space. As with the buildings, the heights from the DTM are used. These reflect the water surface and do not take into account any protruding objects. In addition, since the quantification of visible blue space is the

Fig. 1 Workflow: part 1

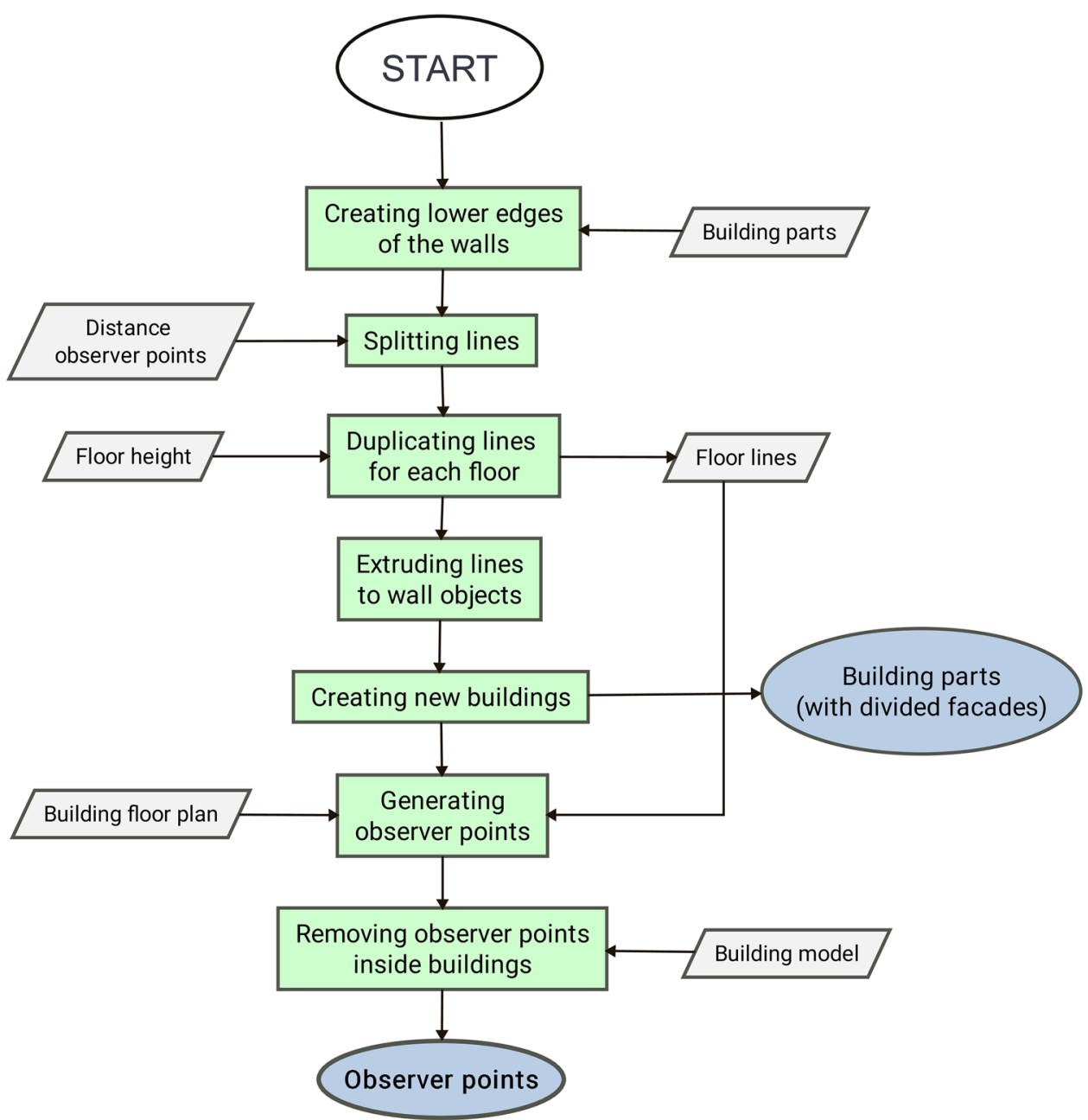




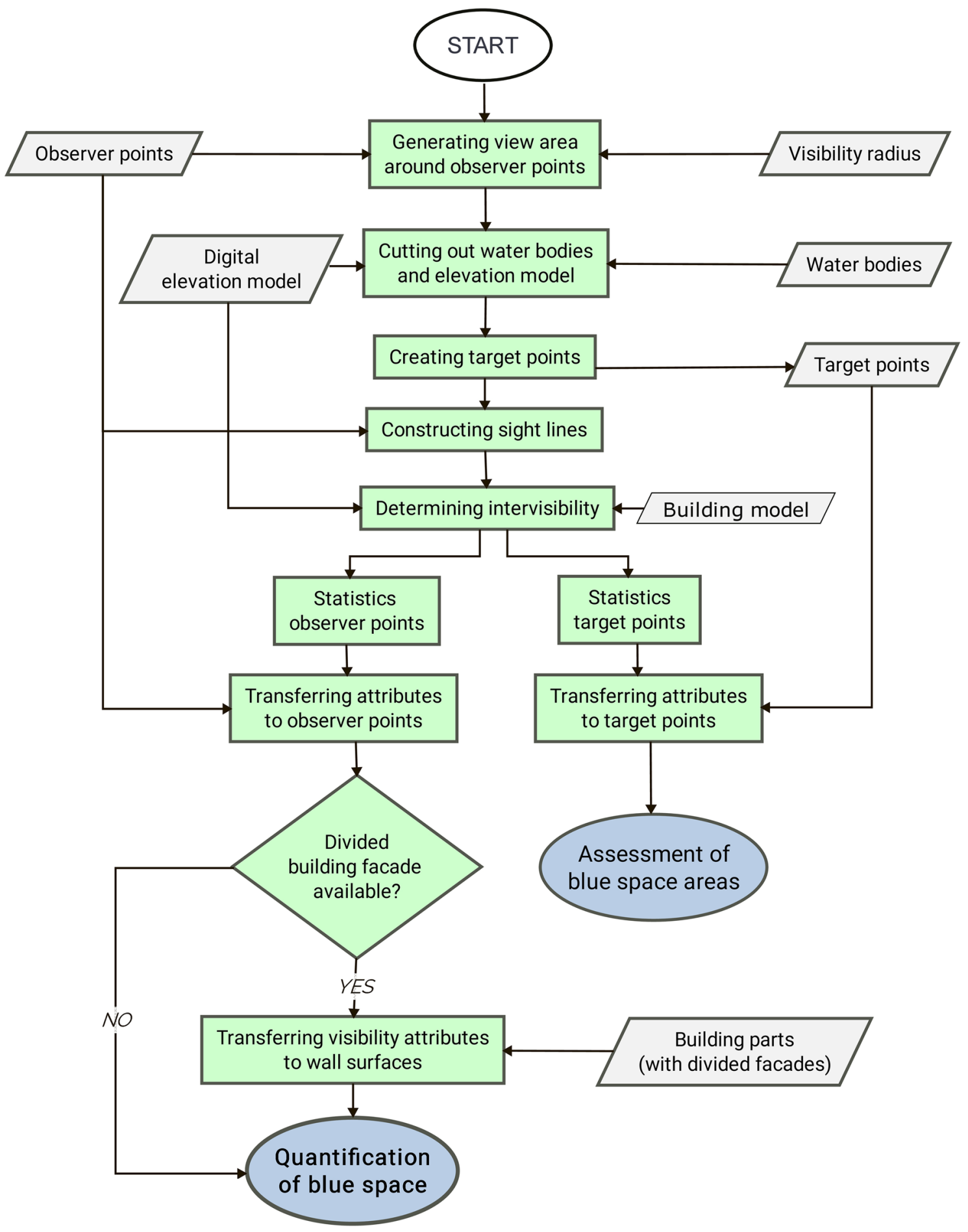

Fig. 2 Workflow: part 2

objective of visual analysis, the location of the water bodies is needed as a vector data set.

Requirements for the development of the planning tool were defined and input parameters classified according to the priority of their implementation (see Table 1). Priority I includes parameters that are imperative for evaluating the buildings in terms of visible blue space. Priority II describes possible enhancements that could be added within the scope of the project, but were not a condition for running the tool. In the implementation, all these parameters could be accounted for. 
Fig. 3 Planning tool in ArcGIS Pro
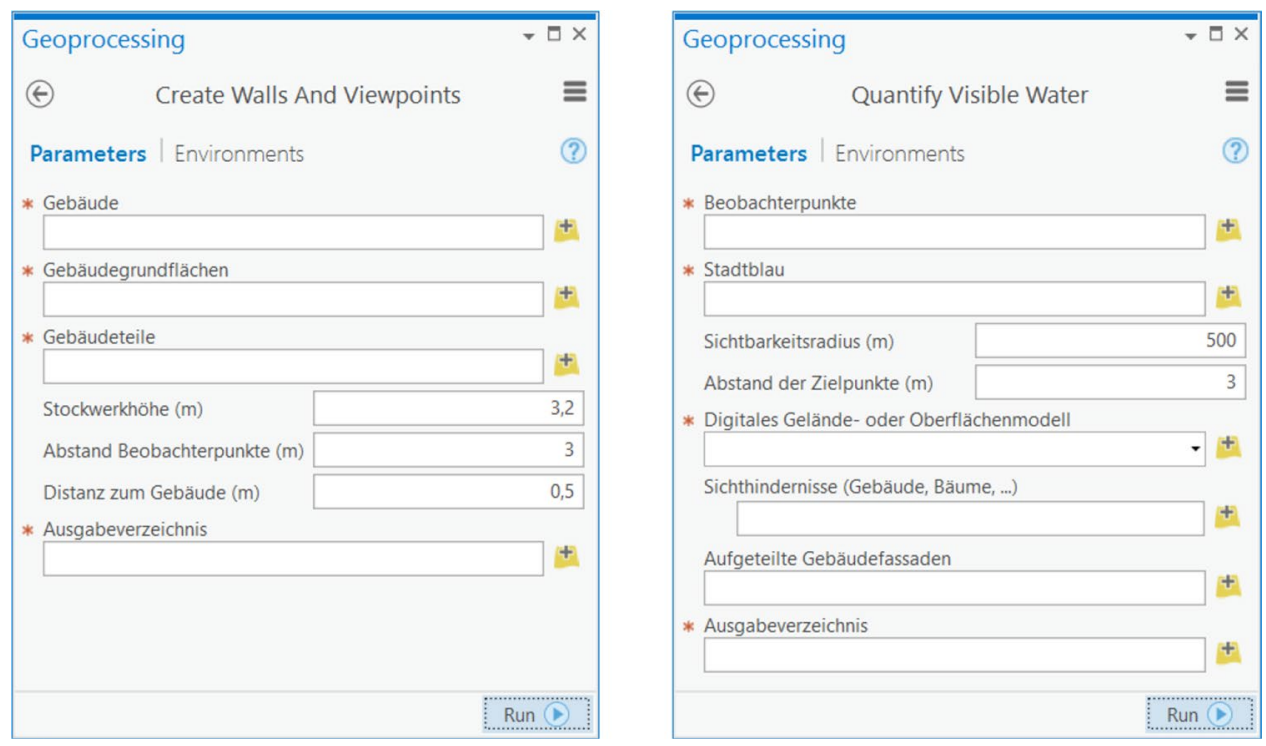

Table 1 Prioritization of input parameters

\begin{tabular}{ll}
\hline Priority & Input parameters \\
\hline Priority I & 3D City Model LoD2 (CityGML) \\
& Digital Terrain Model or Digital Surface Model \\
& Target areas: water bodies, but also green space or other area types should be possible \\
& Variable distance between observer points \\
Priority II & Variable buffer for observer points: only target areas within buffers are considered in \\
& the visibility analysis \\
& Adding own observer points or usage of user-defined points only
\end{tabular}

\subsection{Floor-Specific Viewpoints}

As an observer or visual point of view, three-dimensional points are denoted here, from which the visibility analysis proceeds. To obtain detailed results, the analysis has to be carried out based on window-specific observer points. However, since window geometries are only available in the LoD3 model, the observer points are modeled on the building façade using the LoD2 model at a variable horizontal distance. For a building-specific 3D representation of the results, these should finally be transferred to the buildings. For this purpose, the facades will be replaced by new subareas for which one observer point will be created. Depending on the visible blue space area of the observers, the associated façade area is visualized (cf. Sect. 4).

The buildings of a 3D city model consist of any number of building parts such as walls, floors and roof surfaces. To generate new façade elements, only the walls are needed. The method for dividing the wall elements is done in three steps. First, for each wall, the bottom edge, defined by the two points with the smallest height, is created as a polyline. In the second step, these polylines are divided according to the desired width of the facade elements. Finally, the split lines can be duplicated according to the number of floors and the corresponding height, forming floor outlines. The height of each wall element can be determined from the difference between the top and bottom edges. With this height and the floor height, the number of floors is determined. The height of the lower edge represents the initial value for all subsequent storey heights. Finally, new wall elements are created by extruding the duplicated lines. For each new wall element, an observer point is created which serves as the initial object of the visibility analysis.

\subsection{Visibility Analysis and Evaluation}

To increase performance, the transferred data records are reduced at the beginning of the workflow. On the one hand, the area to be analyzed is restricted by a visibility radius (see Fig. 4). A buffer around all observer points defines the field of view at the specified distance. The digital elevation model as well as the water bodies are overlaid to this area. Since not only complete water bodies but also partial areas are to be checked for visibility, grid points arranged on the water bodies are created. These serve as target points in the visibility analysis and receive their height from the digital 
Fig. 4 Definition of visibility area

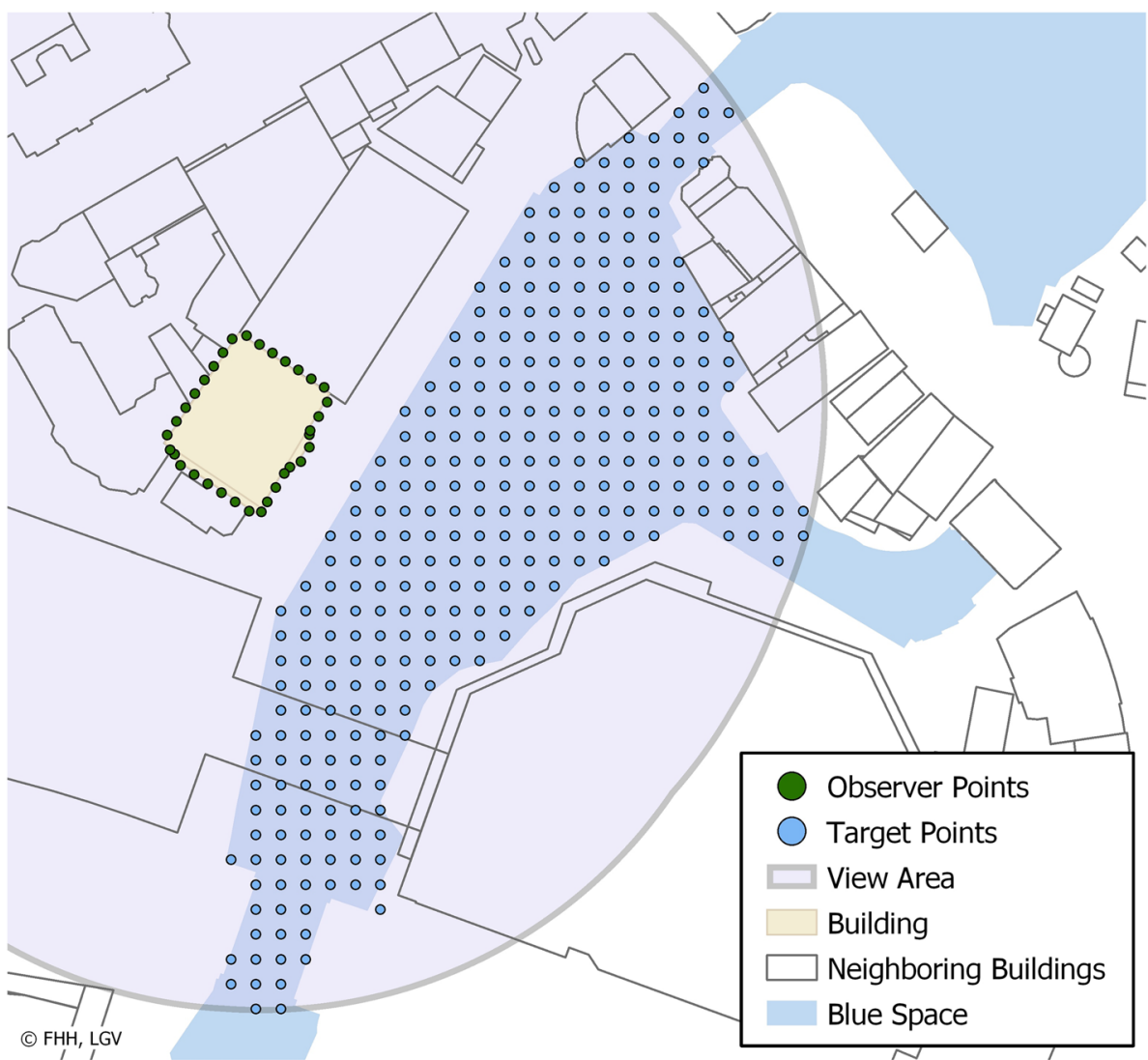

elevation model. The selected distance of the target points (grid width) determines the sum of the points to be generated on the water surfaces. Since the visibility analysis generates a line of sight from each observer point to each target point, the number of target points determines the number of sight lines to be generated and thus significantly influences the tool's calculation effort and the accuracy of the delimitation of the water bodies (cf. Sect. 5).

With the observer points and the target points on the blue space areas, the visibility analysis can be carried out. The 3D city model, together with the Digital Elevation Model, serves to describe the obstructions. Figure 5 illustrates the determined visibility of lines of sight between observer point and target point.

The visibility analysis is the basis for determining the visible blue space. Each line of sight has a reference both to its observer point on the building facade and to the target point on the water body surface. Consequently, with all lines of sight and their attributes of visibility, an evaluation for the visible blue space can be created for each observer point. Since an arbitrary number of lines of sight emanate from one observer point, the quantification of the visible blue space can be carried out with a statistical evaluation of the lines of sight. For each observer point, the number of visible water body points is determined. Taking into account the grid width of the water areas, the visible blue space area can be calculated for each observer point. Conversely, the frequencies with which each target point on the water body surfaces can be seen from any observer points can be determined.

\section{Visualization}

With the developed planning tool, the simulated, virtually window-precise results can be aggregated to a buildingspecific quantification of visible blue space. The urban environment of any building is examined for this with a visibility analysis from different points of view on visible surface waters. To take into account the results in planning processes, the building parts can be represented in color according to the visible water surface (see Fig. 6).

The gradually graded green-colored façade elements represent the visible blue space area calculated for their respective observation point. The visibility ranges from $0 \mathrm{~m}^{2}$ (white) to a visible area of $6000 \mathrm{~m}^{2}$ (dark green). It becomes apparent that in particular from the upper two floors a notable amount of blue space $\left(>5000 \mathrm{~m}^{2}\right)$ is visible. The lower two floors show a visible blue space area of mostly 3000-5000 $\mathrm{m}^{2}$, but corner areas with a maximum of $3000 \mathrm{~m}^{2}$ see less blue space. Looking at the side of the building, it is noticeable that blue space can be seen only from the front area. For the remaining side surfaces, the view 
Fig. 5 Visibility of lines of sight

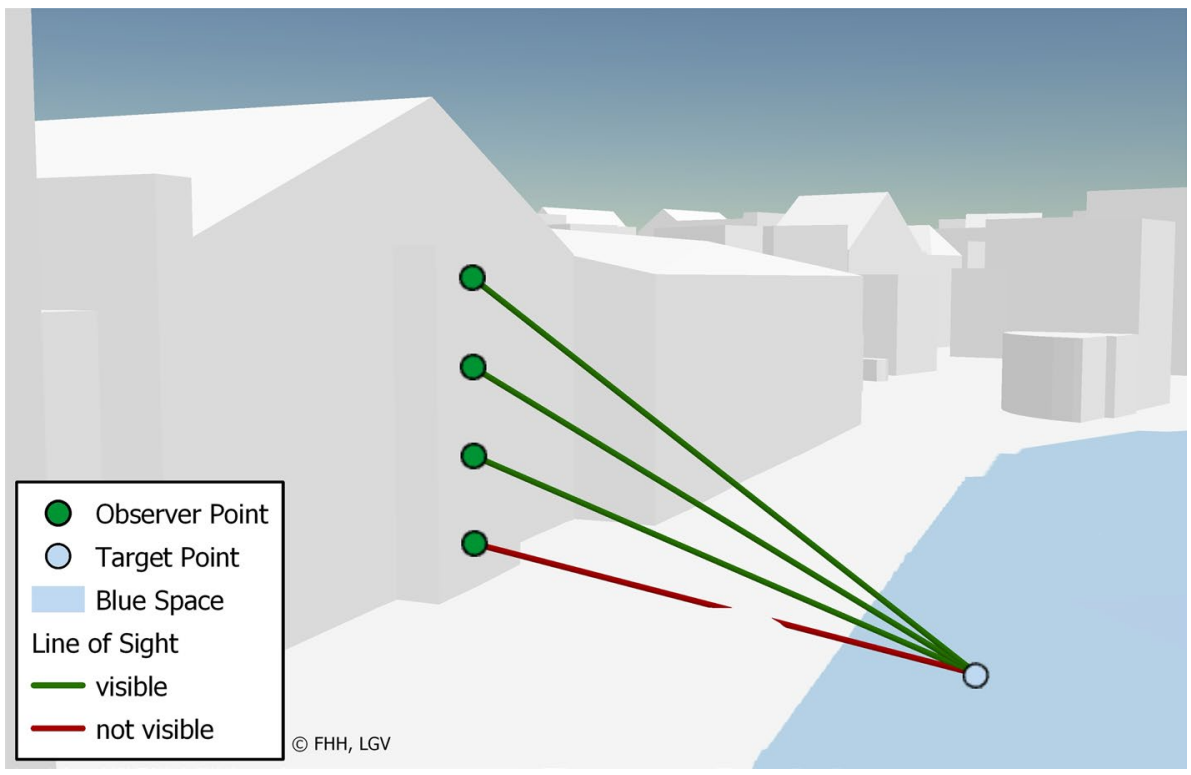

Fig. 6 Visible blue space of a building

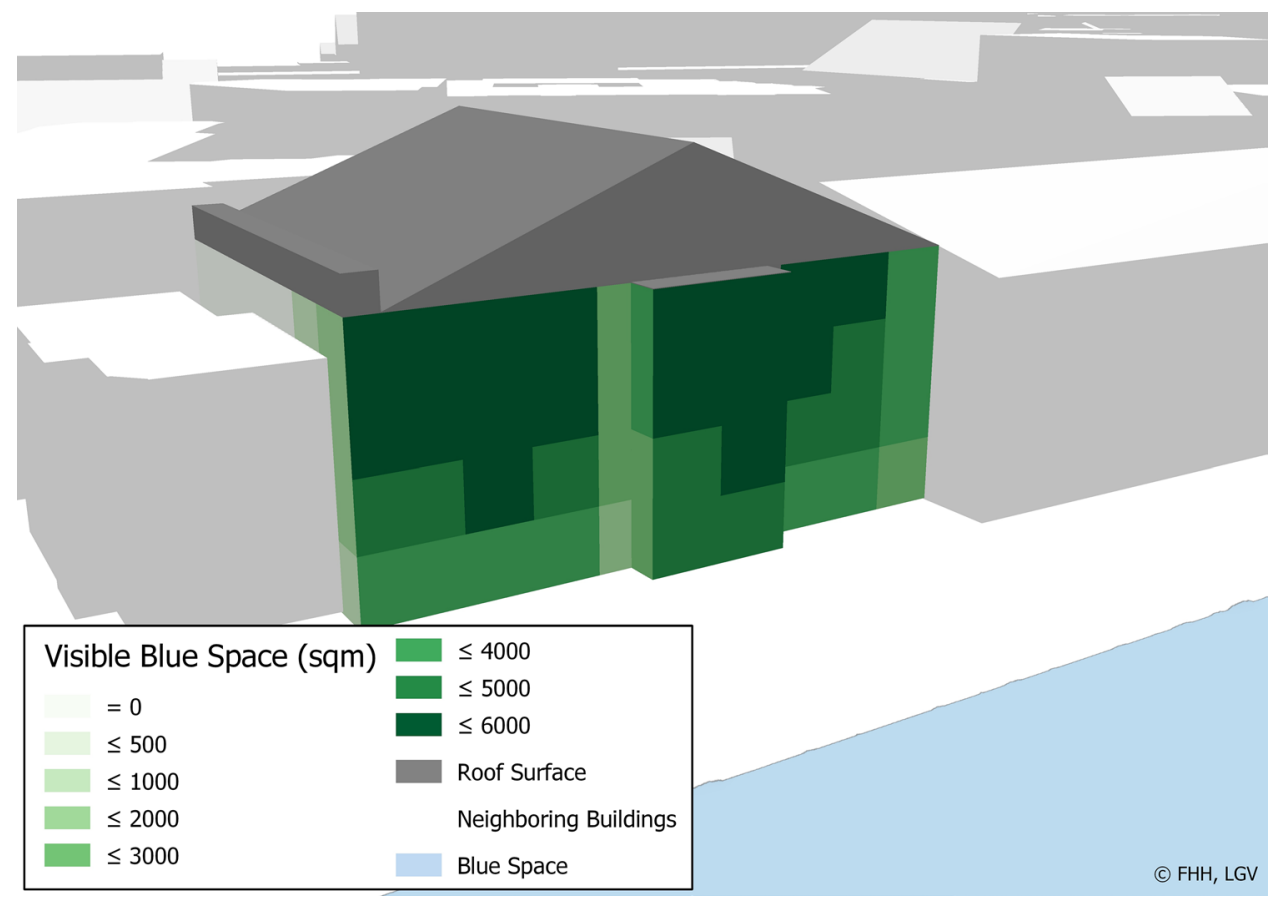

is obstructed by the neighboring building. To illustrate the visual restriction through neighboring buildings, they are also displayed. Roof surfaces that are not included in the analysis are grayed out.

From the results of the visibility analysis, in addition to the quantification of visible blue space, an assessment of the blue space areas can also be carried out (cf. Sect. 3.3). A partial water surface is evaluated with regard to its frequency of existing visibility of observer points, with each target point given the sum of its visibility for this purpose.
Figure 7 shows the result for the analysis of three buildings, a viewing area of $100 \mathrm{~m}$ and a grid of the water body of $3 \mathrm{~m}$. Partial water areas, which are seen from many observer points, are colored in dark green. Areas that are only seen by a few points or not at all are shown in orange or red. 
Fig. 7 Visibility frequency of a water body from surrounding buildings

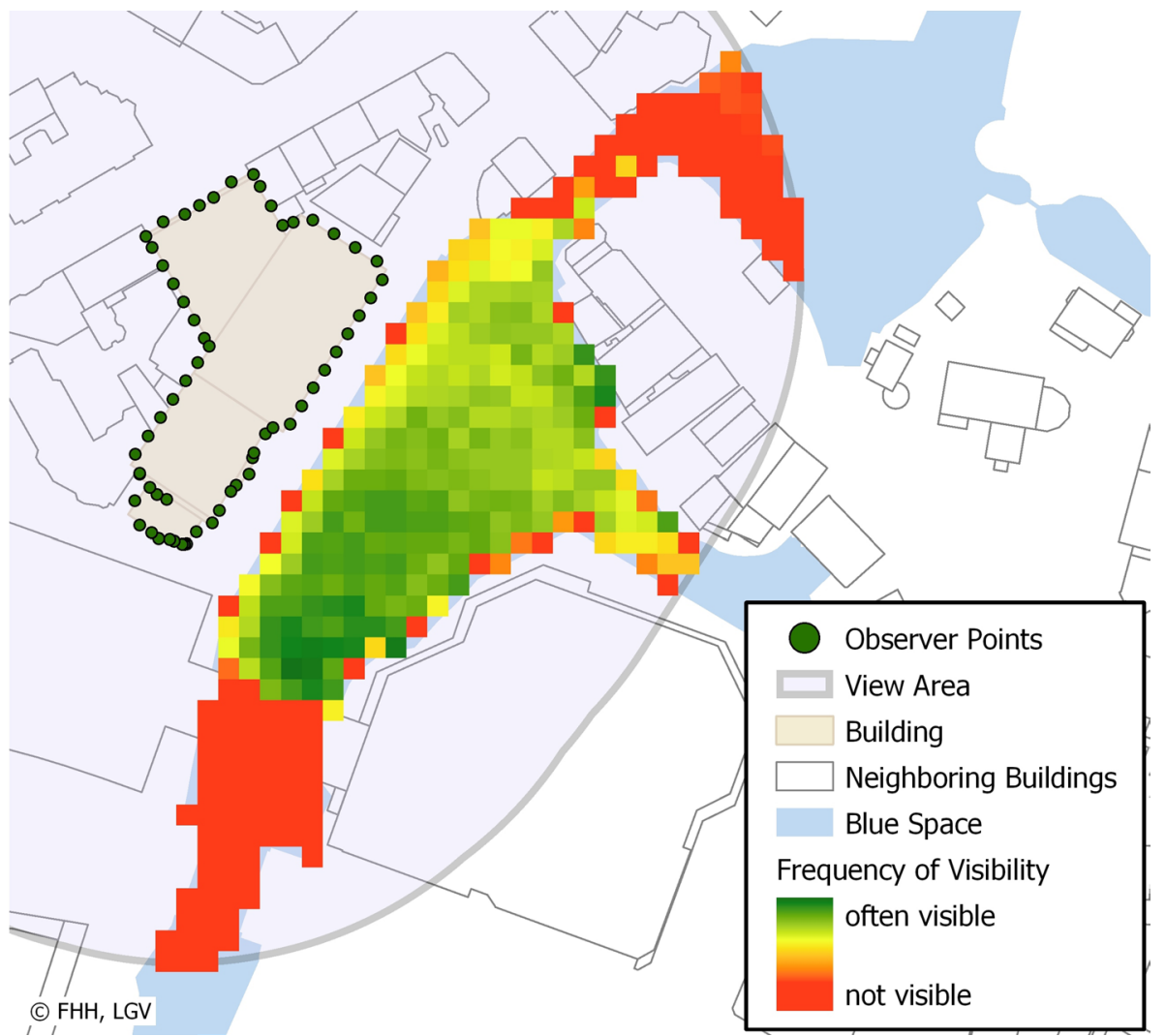

\section{Discussion and Outlook}

The resulting quality of the planning tool depends on the input data provided. For the generation of the observer points, the number of buildings to be analyzed and above all the desired point distance are decisive as to the accuracy of the results. In the visibility analysis, the field of view, the size of the target areas and the distance of target points are influencing factors of runtime and quality. From each observer point to each target point, a line of sight is created. Due to the deteriorated boundary description of water bodies, the result of the visibility analysis loses accuracy as the distance of the target points increases, but at the same time it increases in performance as the number of lines of sight decreases. The developed tool was tested with different observer and target point distances, and the runtime behavior as well as the results were critically evaluated. The test building used (see Fig. 6) had a documented runtime of $1 \mathrm{~min}$-with four storeys, a target distance of $5 \mathrm{~m}$ and about 40,000 visual lines to be created and tested. The tool is thus suitable for small-scale analyses or for the consideration of single buildings. But even in the case that the visible blue space has to be calculated for an entire city, the tool can be used, as this is a unique and not time-critical process.
In the course of the development of the workflow and especially during the implementation of the planning tool, possibilities for extensions and optimizations became apparent. For example, the reduction of the actually visible blue space area by an oblique view or by a long distance is not yet considered. Depending on the vertical angle and distance between the surface and the observer point, there are considerable differences in the actually perceived surface area size. With increasing distance or oblique view the perceived area becomes smaller. For this purpose, sight cones can be introduced into the analysis method instead of lines of sight. Another aspect of extension is a possible categorization of water bodies. Since the target areas can be both park waters as well as lakes, rivers, ponds or streams, a weighting of the water bodies according to their type is conceivable. Moreover, it has not yet been considered that the contiguous visibility of adjacent water bodies from one observer point is further quality feature. From a technical point of view, a need for optimization has become apparent primarily due to the high computational effort for the visibility analyses, especially for large-scale analyses. An amount of data volume as limited as possible should be provided as inputs to the tool, or a corresponding calculation effort should be considered and sufficient storage capacity available for results. In this context, the use of alternative software for better performance and user availability should be taken into account. 


\section{Summary}

For use in ArcGIS Pro, a work flow for the quantification of blue space was developed and implemented. For any buildings of a 3D city model, in addition to the generation of observer points on building facades, a three-dimensional visibility analysis can be carried out automatically. With the methodology presented here, a quantification as well as a visualization - and thus also the communication - of the blue space theme is achievable in the planning process, since the qualitative effect becomes tangible in numbers, i.e. at parts of the building front and the water surface itself. Scenarios can now also be assessed and weighed against each other from the perspective of blue space, which means that the effect of new or removed visual obstructions, as well as variants of new water surfaces can be incorporated into the planning process.

For large-scale analyses with a large number of buildings, longer calculation times have to be taken into account; this appears tolerable for most applications due to the fact that these calculations need only be carried out once. The consideration of health effects of blue space is now given a foundation in all steps of spatial infrastructure economics, which—last but not least—can also be used for evaluation procedures in the real estate industry.

\section{References}

Graf R (2006) Ortsbasierte Sichtbarkeitsanalyse mit digitalen Geländemodellen auf mobilen Endgeräten. http://docplayer.org/42276 94-Ortsbasierte-sichtbarkeitsanalyse-mit-digitalen-gelaendemo dellen-auf-mobilen-endgeraeten.html. Accessed 02 Jan 2018

Kistemann T, Völker S (2014) Wie urbane Wasserflächen die Gesundheit fördern. In: Nachrichten der Akademie für Raumforschung und Landesplanung, 2014 (4), S. 7-10. https://shop.arl-net.de/ nachrichten-der-arl-4-2014.html. Last access 14 Dec 2017

Schmidt G, Gustedt E, Reimann S, Sondermann M, Warner B (2017) Lässt sich Gesundheit planen? Diskussionen und Ergebnisse der Workshops beim ARL-Kongress am 11. und 12. Mai 2017. In: Nachrichten der Akademie für Raumforschung und Landesplanung, 2017 (03), S. 30-32. https://shop.arl-net.de/media/direct/ pdf/nachrichten/2017-3/NR_3_2017_Kongress_S30-32_onlin e.pdf. Last access 19 Dec 2017 